\title{
A Phase I Trial of Oxaliplatin for Intraperitoneal Hyperthermic Chemoperfusion for the Treatment of Peritoneal Surface Dissemination from Colorectal and Appendiceal Cancers
}

\author{
John H. Stewart IV, MD¹, Perry Shen, MD¹, Greg Russell, MS², Joyce Fenstermaker, RN¹, \\ Libby McWilliams, BS ${ }^{1}$, Faith M. Coldrun, $\mathrm{MS}^{3}$, Keith E. Levine, $\mathrm{PhD}^{4}$, Bradley T. Jones, \\ $\mathbf{P h D}^{5}$, and Edward A. Levine, MD ${ }^{1}$ \\ ${ }^{1}$ Surgical Oncology Service, Department of General Surgery, Medical Center Blvd, Wake Forest \\ University School of Medicine, Winston-Salem, NC 27157, USA \\ ${ }^{2}$ Biostatistics Section, Department of Public Health Sciences, Wake Forest University School of \\ Medicine, Winston-Salem, NC, USA \\ ${ }^{3}$ Department of Physics, Wake Forest University, Winston-Salem, NC, USA \\ ${ }^{4}$ Research Triangle Institute, Research Triangle Park, NC, USA \\ ${ }^{5}$ Department of Chemistry, Wake Forest University, Winston-Salem, NC, USA
}

\begin{abstract}
Background-Cytoreductive surgery with intraperitoneal hyperthermic chemoperfusion (IPHC) has evolved into a promising approach for peritoneal surface malignancy. A large body of literature suggests that oxaliplatin has excellent cytotoxicity against colorectal cancer. Therefore, we undertook a phase I evaluation of IPHC with oxaliplatin for peritoneal dissemination from colorectal and appendiceal cancers to establish the dose-limiting toxicity (DLT) and the maximum tolerated dose (MTD).
\end{abstract}

Methods-Cohorts of three patients underwent cytoreductive surgery followed by a 2-h IPHC with escalating doses of oxaliplatin at a target outflow temperature of $40^{\circ} \mathrm{C}$. The initial peritoneal oxaliplatin dose was $200 \mathrm{mg} / \mathrm{M}^{2}$ with increases planned in $50 \mathrm{mg} / \mathrm{M}^{2}$ increments. Plasma and perfusate samples were collected during the IPHC and evaluated using emission spectrometry techniques. Normal tissue and tumor samples were collected before and after the IPHC for analysis. DLT was defined as a grade 3 toxicity lasting 5 days.

Results-Fifteen patients were enrolled at two dose levels. Peritoneal fluid areas under the curve (AUCs) were above those of plasma. Additionally, intratumoral oxaliplatin was similar to that of surrounding normal tissue. Dose-limiting toxicities at $250 \mathrm{mg} / \mathrm{M}^{2}$ were observed in two of three patients enrolled in this study.

Conclusion-We found that IPHC with $200 \mathrm{mg} / \mathrm{M}^{2}$ of oxaliplatin is well tolerated and is the MTD for a 2-h chemoperfusion. Higher doses are not feasible with this perfusion protocol given the significant toxicities associated with $250 \mathrm{mg} / \mathrm{M}^{2}$ oxaliplatin. Based on the data from this phase I study, we propose to conduct further studies with oxaliplatin delivered at $200 \mathrm{mg} / \mathrm{M}^{2}$.

\section{Keywords}

Oxaliplatin; Surgery; Intraperitoneal hyperthermic chemoperfusion; Carcinomatosis; Phase I trial

C 2008 The Society of Surgical Oncology, Inc.

Address correspondence and reprint requests to: John H. Stewart IV, MD; jhstewar@wfubmc.edu. 
Peritoneal carcinomatosis is uniformly a terminal disease with a median survival of 6 months. ${ }^{1,2}$ Advanced disease is often present at the time the primary tumor is diagnosed and systemic chemotherapy generally provides limited benefit. ${ }^{1,3}$ The use of cytoreductive surgery along with intraperitoneal hyperthermic chemotherapy (IPHC) however, has evolved into an a promising approach for peritoneal surface malignancy. ${ }^{4-7}$ IPHC provides a pharmacokinetic advantage to the treatment of local-regional disease relative to systemic therapy because it bypasses the peritoneal-plasma partition. ${ }^{8,9} \mathrm{~A}$ unique challenge is to identify agents that offer optimal therapeutic benefits while minimizing toxicity. Although a variety of agents have been investigated for use in the setting of IPHC for the treatment of peritoneal dissemination of colorectal and appendiceal cancers, most have either limited activity against colorectal cancer or lack additional therapeutic effect from the addition of hyperthermia. Mitomycin C is the most commonly utilized agent for IPHCand has been used since the early 1990s. The availability of newer and potentially more active agents suggests a potential for improved efficacy.

Oxaliplatin is a diaminocyclohexane-platinum compound that is active in a variety of solid tumor types and is licensed in the USA for the treatment of colorectal cancer. Oxaliplatin is an attractive agent for IPHC because it not only has proven activity against colorectal cancer cells, ${ }^{10}$ but it is also potentiated by hyperthermia. Previous data demonstrate that the concentration of oxaliplatin required to induce cytotoxicity is significantly reduced when delivered in the context of hyperthermia. ${ }^{11,12}$ In a preliminary set of experiments from our group, hyperthermia sensitized both HCT-29 and RKO cell lines to the cytopathic affects of oxaliplatin. The oxaliplatin $\mathrm{IC}_{50}$ for HCT 116 and RKO colorectal cancer cells was reduced from $144 \mu \mathrm{M}$ and $89 \mu \mathrm{M}$ to $57 \mu \mathrm{M}$ and $59 \mu \mathrm{M}$, respectively, after exposing these cell lines to mild hyperthermia at $40^{\circ} \mathrm{C}$ for $2 \mathrm{~h}$ (unpublished data from the laboratory of John Stewart). The superior cytotoxicity of oxaliplatin makes it an excellent drug to study in the setting of peritoneal surface dissemination of colorectal and appendiceal cancers. Therefore, we initiated this dose escalation trial to evaluate the safety of using oxaliplatin in the perfusate for intraperitoneal hyperthermic chemotherapy at the time of cytoreductive surgery.

\section{PATIENTS AND METHODS}

\section{Patient Eligibility}

All patients were older than 18 years with histologically confirmed colorectal or appendiceal cancer and had an Eastern Cooperative Group performance status of 0-2. Acceptable bone marrow (absolute neutrophil count $\geq 1,500 / \mu \mathrm{L}$, platelet count $\geq 100,000 / \mu \mathrm{L}$ ), renal (serum creatinine $\unlhd .5$ ), and hepatic function (serum total bilirubin $\unlhd .5 \mathrm{mg} / \mathrm{dL}$, alkaline phosphatase $\leq \times 3$ the upper limit of normal, and serum oxaloacetic transaminase (SGOT)/ serum glutamic pyruvic transaminase (SGPT) $3 \times$ the upper limit of normal) were required for enrollment in this trial. Ineligibility criteria included an active infection or a fever $238.5^{\circ} \mathrm{C}$ within 3 days of the scheduled day of protocol treatment, central nervous system metastases, known hypersensitivity to any of the components of oxaliplatin, receipt of investigational therapy within 30 days of IPHC (investigational therapy was defined as treatment for which there is currently no regulatory authority approved indication), peripheral neuropathy $\geq$ grade 2, history of allogeneic transplant, and known HIV or hepatitis B or C infection. Patients with prior malignancy within the past 5 years were considered to be ineligible except for curatively treated basal cell carcinoma of the skin, cervical intra-epithelial neoplasia, or localized prostate cancer with a current prostate specific antigen (PSA) of $<1.0 \mathrm{mg} / \mathrm{dL}$ on two successive evaluations. 


\section{Study Design}

This was a nonrandomized, open-label phase I trial in patients with stage IV peritoneal carcinomatosis from colorectal and appendiceal cancers. This trial was reviewed and approved by the Wake Forest University Health Sciences Institutional Review Board. All patients signed a written informed consent prior to study enrollment. The dose escalation scheme was based on a modified Fibonacci series. Dose-limiting toxicity (DLT) was defined as grade 3 toxicity that was attributable to the intraperitoneal administration of oxaliplatin and exceeded 5 days in duration. Three patients were assigned to a dose of $200 \mathrm{mg} / \mathrm{M}^{2}$ of oxaliplatin, which is roughly 2.5 times the intravenous dose delivered to patients with metastatic colorectal cancer, to verify that this dose would be tolerated in patients with peritoneal carcinomatosis. We then proceeded to escalate to the next dose level of $250 \mathrm{mg} /$ $\mathrm{M}^{2}$ after at least 10 days elapsed since the completion of the first cohort to rule out unacceptable DLT. Two of three patients demonstrated DLTs in this cohort, so $200 \mathrm{mg} / \mathrm{M}^{2}$ was considered the maximum tolerated dose (MTD). After defining the MTD, an additional nine patients were enrolled to more fully evaluate toxicities and pharmacokinetics at 200 $\mathrm{mg} / \mathrm{M}^{2}$.

Adverse events were described using the National Cancer Institute Common Terminology (NCI CT3.0) criteria. Frequency and severity of adverse events were described according to the NCI CTCAE V 3.0 body system and severity criteria. In addition, the frequency of grade 3 or 4 adverse clinical events and laboratory abnormalities as well as causality were recorded according to the NCI CTCAE criteria.

\section{Study Procedures}

All participants underwent preoperative mechanical and antibiotic bowel preparation. Potential ostomy sites were marked by the surgeon or the enterostomal nurse prior to surgery. The IPHC was preceded by a complete cytoreduction to maximize its therapeutic benefit, as described elsewhere. ${ }^{5}$ The goal of cytoreductive surgery was to render the patient free of disease. Resection of the peritoneum by stripping it off the abdominal wall combined with multivisceral resections, as indicated by disease adherent to intra-abdominal organs (such as splenectomy, large and small bowel resection, uterus, etc.), were utilized for maximal tumor debulking. All patients in this study had $2 \mathrm{~cm}$ of tumor and $2 \mathrm{~cm}$ of normal peritoneum marked and left in place during the IPHC and removed immediately after perfusion to evaluate tissue drug levels.

Patients were cooled to a core temperature of about $34-35^{\circ} \mathrm{C}$ by passive measures during cytoreduction. After the completion of cytoreductive surgery, peritoneal perfusion catheters were placed percutaneously. Two inflow catheters $(22 \mathrm{~F})$ were directed beneath the left and right hemidiaphragms. Two outflow catheters $(32 \mathrm{~F})$ were placed in the pelvis. Drainage bulbs were attached to the end of the outflow cannulae to avoid suction injury to the bowel. Temperature probes were placed on the inflow and outflow catheters. The abdominal skin incision was temporarily closed with a running suture to prevent leakage of peritoneal perfusate. A perfusion circuit was then established with $3 \mathrm{~L}$ of D5W solution. Flow rates of approximately $800-1,000 \mathrm{~mL} / \mathrm{min}$ were maintained using a roller pump managed by a perfusionist. The pelvic catheters drained to a standard cardiotomy reservoir containing a coarse filter for debris and to reduce foaming. The circuit continued through a single roller pump, a heat exchanger, and then to the patient. Heated water was be pumped to the heat exchanger device from a Blanketrol ${ }^{\circledR}$ (Cincinnati Sub-Zero Products, Inc., Cincinnati, OH) heating/cooling blanket reservoir. The temperature of the fluid in the patient, water bath, patient-return, and patient-directed tubing were monitored using stainless-steel couplers with temperature probe connectors and needle probes at the tips of one inflow and one outflow cannula. 
Once outflow temperatures exceeded $39^{\circ} \mathrm{C}$, oxaliplatin was added to the perfusate. A maximum inflow temperature of $42.5^{\circ} \mathrm{C}$ was tolerated during the perfusion, with a target outflow temperature of $40^{\circ} \mathrm{C}$. The total perfusion time after the initial addition of oxaliplatin was $120 \mathrm{~min}$. The abdomen was gently massaged throughout the perfusion to improve drug distribution to all peritoneal surfaces. Following the perfusion, the peritoneum was washed out with $3 \mathrm{~L}$ of crystalloid and the peritoneum drained passively. The skin was then opened, and the cannulae removed under direct vision. The previously marked residual tumor was resected after the perfusion and submitted for tissue and intratumoral oxaliplatin levels. The abdomen was inspected and the required anastomoses or stomas were performed. The fascia and skin were then closed in a standard fashion.

\section{Pharmacokinetics Methods}

Each patient had 20 heparinized blood samples of $5 \mathrm{~mL}$ drawn during the study for pharmacokinetics studies. The samples were drawn at time 0 and at 10 - min increments until the completion of the perfusion. Samples were also collected at 10, 20, 30, 60, and $90 \mathrm{~min}$ and at 12 and $24 \mathrm{~h}$ after IPHC. Five milliliters of peritoneal fluid samples were collected at time 0 and at 10-min increments until the completion of the perfusion. The samples were stored at $-70^{\circ} \mathrm{C}$ until analysis.

Two types of tissues were collected before and after the IPHC. Before the perfusion with oxaliplatin, a 2- cm-diameter piece of normal peritoneum and samples of peritoneal surface malignancy were collected for pharmacokinetic analysis. Upon completion of the perfusion, another $2 \mathrm{~cm}$ sample of peritoneum as well as the tumor nodule which was marked and left in situ during the perfusion were collected for analysis of oxaliplatin levels. All tissue was snap-frozen in liquid nitrogen and stored at $-70^{\circ} \mathrm{C}$ until analysis.

Platinum levels were determined by inductively coupled plasma atomic emission spectrometry (Thermo iCAP 6500 ICP-OES). A $1.00 \mathrm{~mL}$ aliquot of each fluid sample was added to a $15 \mathrm{~mL}$ digestion tube. The samples were acidified with $0.50 \mathrm{~mL}$ concentrated nitric acid and $0.50 \mathrm{~mL}$ concentrated hydrochloric acid. The solution was shaken with a vortex device, and then heated in a water bath at $90^{\circ} \mathrm{C}$ for $1 \mathrm{~h}$. After cooling, the final solution volume was made up to $5.0 \mathrm{~mL}$ with deionized water, so the overall dilution factor for the original fluid sample was 5. Finally, the diluted samples were centrifuged for $30 \mathrm{~min}$ at $3000 \mathrm{rpm}$, and the supernatant was analyzed.

Tissue sample mass ranging from 0.005 to $0.200 \mathrm{~g}$ was determined accurately with an analytical balance. The samples were added to a $50 \mathrm{~mL}$ digestion tube, and acidified with $2.5 \mathrm{~mL}$ concentrated nitric acid and $2.5 \mathrm{~mL}$ concentrated hydrochloric acid. The acid solutions were heated on a hot block for $12 \mathrm{~h}$ at $60^{\circ} \mathrm{C}$. The samples were then diluted to 25.0 $\mathrm{mL}$ before being analyzed by inductively coupled plasma atomic emission spectrometry.

All pharmacokinetics values were calculated using OriginPro 8 SR1 (Hearne Scientific Software, Chicago, IL). The area under the curve (AUC) was determined numerically by using two adjacent values to form a trapezoid, and the area of all of the trapezoids was then calculated. The half-life of platinum was calculated by fitting an exponentially decaying function from the peak concentration of platinum.

\section{Statistical Analysis}

Descriptive statistics, including frequencies and proportions for categorical data and means, standard deviations, and ranges for continuous measures, were calculated. Categorical data were analyzed using a Fisher's exact test (an exact form of the chi-square), while continuous data were analyzed using a Wilcoxon two-sample test (this test takes into account small 
sample sizes in the study groups). A $P$-value less than 0.05 indicated significant differences in the outcome measure between the two study groups.

\section{RESULTS}

\section{Patient Demographics}

Fifteen patients were enrolled between March 22, 2007 and November 19, 2007. Twelve patients were enrolled at the $200 \mathrm{mg} / \mathrm{M}^{2}$ dose while three were enrolled at the $250 \mathrm{mg} / \mathrm{M}^{2}$ dose. Table 1 lists patient demographics and baseline data. The treatment groups were essentially identical with respect to patient characteristics. The mean age was 55.5 \pm 10.9 years (range 39-73 years) with a slight female preponderance. Most of the patients enrolled in this study had appendiceal tumors. The majority of patients enrolled in this trial underwent treatment of their disease prior to enrollment in this trial. Seven patients were treated with previous chemotherapy (six were treated with systemic oxaliplatin) while one patient had undergone prior IPHC with mitomycin C.

\section{Operative and Perfusion Data}

The operative and perfusion data are summarized in Table 2. The length of the operation (range 363-715 $\mathrm{min}$ ) was primarily related to the extent and location of disease at exploration. The goal of cytoreductive surgery was to render the patient free of disease. This varied from simple lysis of adhesions and omentectomy to multivisceral resections in other instances. The quantity of residual disease was recorded by the primary surgeon; the resection status of all patients undergoing IPHC on this protocol is listed in Table 2. The mean outflow temperature of the perfusate in this study was $40.6 \pm 0.5^{\circ} \mathrm{C}$. Patients received an average of three units of packed red blood cells during the debulking portion of the procedure. This reflects the magnitude of the cytoreductive procedures required to render these patients free of macroscopic disease.

\section{Toxicity}

Three patients were initially assigned to a dose of $200 \mathrm{mg} / \mathrm{M}^{2}$ of oxaliplatin to verify that this dose would be tolerated in patients with peritoneal carcinomatosis. We then proceeded to escalate to the next dose level of $250 \mathrm{mg} / \mathrm{M}^{2}$. Enrollment in the second cohort was stopped after two patients developed DLTs lasting longer than 5 days. One patient experienced profound leukopenia on postoperative day 2 that was resistant to granulocyte colony stimulating factor. This patient also experienced grade 5 thrombocytopenia and died of bone marrow suppression on postoperative day 4 . An additional patient in the second cohort presented with grade 3 thrombocytopenia that resolved after 1 week. With 2/3 patients experiencing high-grade toxicity at this dose level, nine additional patients were enrolled into the $200 \mathrm{mg} / \mathrm{M}^{2}$ cohort and no DLTs were observed in these patients. Therefore, $200 \mathrm{mg} / \mathrm{M}^{2}$ represented the MTD for this study.

The cumulative experience of clinical toxicity occurring in all 15 patients is summarized in Table 3. Peritoneal delivery of $200 \mathrm{mg} / \mathrm{M}^{2}$ of oxaliplatin was well tolerated. Patients in this cohort experienced minor, short-lived toxicities with the most common toxicity being thrombocytopenia. Although grade 1 or 2 leukopenia occurred in a third of the patients in the first cohort, it uniformly resolved without cytokine support. A few grade 3 and 4 toxicities were seen in patients treated with $200 \mathrm{mg} / \mathrm{M}^{2}$ of oxaliplatin, but these toxicities resolved in fewer than 5 days and were therefore not considered DLTs.

\section{Pharmacokinetics}

An important aspect of understanding the feasibility of utilizing oxaliplatin as the chemotherapeutic agent for IPHC is defining the pharmacokinetic profile of this drug during 
a 2-h peritoneal perfusion. Figure 1 demonstrates the concentration of platinum in the peritoneal perfusate over time, while Table 4 delineates the pharmacokinetics of intraperitoneal oxaliplatin during IPHC. Despite significant interindividual variation, the maximum concentration of oxaliplatin in the perfusate was seen at the beginning of the perfusion and it gradual decreased to $14.0 \pm 4.3 \mathrm{mg} / \mathrm{L}$ in the $200 \mathrm{mg} / \mathrm{M}^{2}$ cohort and $15.9 \pm 2.9$ $\mathrm{mg} / \mathrm{L}$ in patients treated at the $250 \mathrm{mg} / \mathrm{M}^{2}$ dose level. The drug half life $\left(t_{1 / 2}\right)$ in cohorts 1 and 2 were similar at $70.1 \pm 23.8 \mathrm{~min}$ and $65.3 \pm 10.2 \mathrm{~min}$, respectively. During IPHC, peritoneal exposure to the drug, as defined by the AUC, was $49.6 \pm 8.6 \mathrm{mg} / \mathrm{L} \mathrm{h}$ in patients treated at the $200 \mathrm{mg} / \mathrm{M}^{2}$ dose and $62.7 \pm 10.2 \mathrm{mg} / \mathrm{L} \mathrm{h}$ in patients treated at the $250 \mathrm{mg} / \mathrm{M}^{2}$ dose.

Figure 2 demonstrates the concentration of platinum in the plasma over $24 \mathrm{~h}$. Additionally, Table 4 presents the pharmacokinetics of oxaliplatin both during and after IPHC. The maximum concentration of platinum in plasma was seen at $70 \mathrm{~min}$ for both cohorts. The peak plasma concentration of platinum for patients treated at $200 \mathrm{mg} / \mathrm{M}^{2}$ was $2.2 \pm 0.77 \mathrm{mg} / \mathrm{L}$ while that for patients treated at $250 \mathrm{mg} / \mathrm{M}^{2}$ was $3.2 \pm 0.6 \mathrm{mg} / \mathrm{L}(P=0.03)$. Thereafter, plasma platinum concentrations slowly decreased at a $t_{1 / 2}$ of $94.2 \pm 64.8 \mathrm{~min}$ for cohort 1 and $61.2 \pm 5.0 \mathrm{~min}$ for cohort 2. Fourteen of 15 patients demonstrated detectable levels of platinum in the plasma at $24 \mathrm{~h}$ after IPHC. Patients treated with $200 \mathrm{mg} / \mathrm{M}^{2}$ had an average of $0.66 \pm 0.4 \mathrm{mg} / \mathrm{L}$ of platinum in the plasma $24 \mathrm{~h}$ post-perfusion, whereas patients treated with $250 \mathrm{mg} / \mathrm{M}^{2}$ had an average of $0.77 \pm 0.3 \mathrm{mg} / \mathrm{L}$ platinum in the plasma at the same time point. The plasma AUC for oxaliplatin for the $200 \mathrm{mg} / \mathrm{M}^{2}$ cohort was $23.2 \pm 11.4 \mathrm{mg} / \mathrm{L} \mathrm{h}$ while that for the $250 \mathrm{mg} / \mathrm{M}^{2}$ cohort was $31.1 \pm 3.0 \mathrm{mg} / \mathrm{L} \mathrm{h}$. In contradistinction to the AUC data presented for peritoneal fluid, the plasma time points encompass the entire 24-h treatment period. As is shown in Table 5, dramatic increases in tumor, peritoneal, and normal tissue was seen at $2 \mathrm{~h}$. Interestingly, tissue platinum levels were 25 to 32 -fold those seen in the plasma at the conclusion of IPHC.

Analysis of intraoperative pharmacokinetics of oxaliplatin in the peritoneal fluid and plasma during IPHC are shown in Table 6. When evaluated over the course of IPHC, the AUC of peritoneal fluid was $13.7 \pm 4.7$ fold higher than that of plasma in cohort 1 and $12.8 \pm 3.1$ fold higher in cohort 2. The platinum AUC of the peritoneal fluid during the course of the IPHC was significantly higher for the $250 \mathrm{mg} / \mathrm{M}^{2}$ cohort than the $200 \mathrm{mg} / \mathrm{M}^{2}$ cohort $(49.6 \pm 8.6 \mathrm{mg} /$ $\mathrm{L} \mathrm{h}$ versus $62.7 \pm 10.2 \mathrm{mg} / \mathrm{L} \mathrm{h}, P=0.036$ ). Similar findings were noted for the plasma AUC (3.6 $\pm 1.2 \mathrm{mg} / \mathrm{L}$ h versus $4.9 \pm 0.54 \mathrm{mg} / \mathrm{L} \mathrm{h}, P=0.036$ ). During the first hour of IPHC, the oxaliplatin AUC was 20.0 \pm 6.6 times higher in peritoneal fluid than plasma for cohort 1 and 21.5 \pm 3.1 times higher in peritoneal fluid than plasma for cohort 2. As the IPHC progressed to $2 \mathrm{~h}$, the pharmacokinetic advantage was slightly diminished to $9.1 \pm 3.9$ fold in the 200 $\mathrm{mg} / \mathrm{M}^{2}$ cohort and $7.8 \pm 1.6$ fold in the $250 \mathrm{mg} / \mathrm{M}^{2}$ cohort.

\section{CONCLUSIONS}

The clinical utility of cytoreductive surgery and IPHC for peritoneal dissemination of colorectal and appendiceal cancer has been previously described. ${ }^{4,6,7}$ Oxaliplatin is particularly attractive for the treatment of peritoneal carcinomatosis. It is much more active against colorectal cancer than mitomycin $\mathrm{C}$, which has been the most commonly utilized agent. In addition, oxaliplatin's antineoplastic activity is potentiated by hyperthermia, unlike that of 5-fluorouracil.

Prior studies from France have evaluated oxaliplatin for IPHC; however, these studies used a 30 -min perfusion at $42-44^{\circ} \mathrm{C}$. The MTD was found to be $460 \mathrm{mg} / \mathrm{M}^{2} \cdot 13$ Our group has attempted to apply this dose to IPHC as commonly practiced in the USA. Significant hematologic and gastrointestinal toxicities were noted, hence warranting additional 
evaluation. In contradistinction to previous studies, we reevaluated the dosing of oxaliplatin by employing a 2-h perfusion at outflow temperatures of approximately $40^{\circ} \mathrm{C}$ using a closed abdomen technique, as has been our practice since 1991. Given the differences in technique and MTD, it is important to consider our results in the context of the previously reported studies of IPHC with oxaliplatin.

The rationale for IPHC lies in the limited entry of systemic chemotherapy into the peritoneum due to the plasma-peritoneal partition. Drugs delivered into the peritoneal cavity have a clearance that is inversely proportional to the square root of their molecular weight. ${ }^{8,9}$ Because of this partition, drugs without lipophilic properties and high molecular weight have optimal pharmacokinetic profiles for intraperitoneal application. In the present study, we detailed the pharmacokinetic profile of oxaliplatin delivered via a 2-h hyperthermic chemoperfusion. Our data demonstrate three important points with respect to the pharmacokinetic profile of intraperitoneal oxaliplatin. First, peritoneal delivery of oxaliplatin provides a significant treatment advantage to tumor tissue. Tumor cells contained 22- to 25 -fold more drug than did plasma at the conclusion of IPHC, thereby confirming the preferential delivery of oxaliplatin to the tumor cells compared to plasma. Second, tissue exposure to oxaliplatin in the perfusate significantly decreases during IPHC. The intraperitoneal tissue exposure to chemotherapy during IPHC is best described by the $\mathrm{AUC}_{\text {peritoneum} / \text { plasma }}$ value. At $200 \mathrm{mg} / \mathrm{M}^{2}$, the total $\mathrm{AUC}_{\text {peritoneum} / \text { plasma }}$ was $13.7 \pm 4.7$ whereas it was $12.8 \pm 3.1$ at the $250 \mathrm{mg} / \mathrm{M}^{2}$ dose. Interestingly, if one compares the $\mathrm{AUC}_{\text {peritoneum/plasma }}$ for the first half of the procedure to that of the second half, one realizes that the ratio drops significantly. This drop is due to slow accumulation of drug in the plasma and falling peritoneal drug concentration. From these data, one can conclude that the $200 \mathrm{mg} / \mathrm{M}^{2}$ dose of oxaliplatin may best be delivered in divided doses during peritoneal perfusion. Alternatively, a 90-min perfusion could be considered as a small fraction of the AUC occurring in the final $30 \mathrm{~min}$ of a 2-h perfusion. Finally, the data presented in this trial demonstrate that oxaliplatin has a less favorable pharmacokinetic profile than mitomycin $\mathrm{C}$ for IPHC. In the present study, the $\mathrm{AUC}_{\text {peritoneum/plasma }}$ value was $13.7 \pm 4.7$ whereas early pharmacokinetic studies of mitomycin C report a $\mathrm{AUC}_{\text {peritoneum/plasma value of } 75 .}{ }^{14}$ However, due to oxaliplatin's direct activity on the nucleus, it has a steep dose- effect curve; therefore this gradient can have significant therapeutic implications. ${ }^{15}$ In future trials we hope to delineate these therapeutic implications in a prospective, randomized manner.

Intraperitoneal delivery of oxaliplatin was well tolerated in this group of patients. Patients treated at the $200 \mathrm{mg} / \mathrm{M}^{2}$ dose experienced few short-lived toxicities, which did not require intervention. In the present study, 1 of 12 patients exhibited grade 1 neutropenia that spontaneously resolved in 3 days. Although all patients in the $200 \mathrm{mg} / \mathrm{M}^{2}$ cohort demonstrated lymphopenia, this may not be entirely attributable to oxaliplatin since lymphopenia has been described after a variety of operative procedures. ${ }^{16-18}$ Additionally, 6 of 12 patients experienced grade 1 or 2 thrombocytopenia and 1 participant experienced grade 3 thrombocytopenia that resolved without the need for transfusion. These findings compare favorable to the $30 \%$ hematologic toxicity in patients treated with mitomycin-Cbased IPHC. ${ }^{7,19}$ Perhaps the differences in toxicity are related to the propensity of mitomycin $\mathrm{C}$ to induce neutropenia and thrombocytopenia. ${ }^{20}$ This issue can only be resolved in a prospective trial that evaluates hematologic toxicities in patients treated with $200 \mathrm{mg} / \mathrm{M}^{2}$ oxaliplatin to those treated with $40 \mathrm{mg}$ mitomycin C. Compared to previous trials with $460 \mathrm{mg} / \mathrm{M}^{2}$, oxaliplatin resulted in a hematologic toxicity rate of approximately $20 \%$. The higher hematologic toxicity rate in these studies is likely related to greater systemic absorption of oxaliplatin at the higher dose. The maximal plasma concentration of total oxaliplatin was approximately $12 \mathrm{mg} / \mathrm{L}$ in prior studies. ${ }^{13,21}$ However, the maximal plasma concentration was $2.16 \mathrm{mg} / \mathrm{L}$ in our study. These differences in maximal plasma 
concentration of oxaliplatin could therefore account for the differences in toxicities at the two dose levels.

The majority of the clinical benefit from cytoreductive surgery and IPHC is clearly from resection. However, efforts to optimize the perfusion seem clearly warranted. Whether oxaliplatin results in improved outcomes remains to be seen. However, the impressive outcome results for systemic administration suggest a realistic likelihood of efficacy.

The present data support the use of oxaliplatin at $200 \mathrm{mg} / \mathrm{M}^{2}$ for IPHC in the treatment of peritoneal dissemination of colorectal and appendiceal cancers. This treatment regimen is safe and feasible at $200 \mathrm{mg} / \mathrm{M}^{2}$. The toxicity appears lower than our previous experience with mitomycin $\mathrm{C}$. Based on these findings, we plan to propose a larger study that compares toxicity and outcome of patients treated with mitomycin $\mathrm{C}$ to those treated with oxaliplatin.

\section{Acknowledgments}

This study was supported by an Investigator Sponsored Trial grant from Sanofi-Aventis. The authors wish to acknowledge James E. Medlin, Kathryn E. Pharr, Summer N. Hanna, Jiyan Gu, Amal S. Essader, and Carl G. Young for their assistance in evaluating platinum levels in the clinical samples.

\section{References}

1. Blair SL, Chu DZ, Schwarz RE. Outcome of palliative operations for malignant bowel obstruction in patients with peritoneal carcinomatosis from nongynecological cancer. Ann Surg Oncol. 2001; 8:632-7. [PubMed: 11569777]

2. Jayne DG, Fook S, Loi C, et al. Peritoneal carcinomatosis from colorectal cancer. Br J Surg. 2002; 89:1545-50. [PubMed: 12445064]

3. Koga S. Prophylactic and therapeutic continuous hyperthermic peritoneal perfusion for peritoneal metastases of gastric cancer. Gan No Rinsho. 1985; 31:1103-5. [PubMed: 3932711]

4. Levine EA, Stewart JH, Russell GB, et al. Cytoreductive surgery and intraperitoneal hyperthermic chemotherapy for peritoneal surface malignancy: experience with 501 procedures. J Am Coll Surg. 2007; 204:943-53. [PubMed: 17481516]

5. Stewart JH, Shen P, Levine EA. Intraperitoneal hyperthermic chemotherapy for peritoneal surface malignancy: current status and future directions. Ann Surg Oncol. 2005; 12:765-77. [PubMed: 16132375]

6. Stewart JH, Shen P, Russell GB, et al. Appendiceal neoplasms with peritoneal dissemination: outcomes after cytoreductive surgery and intraperitoneal hyperthermic chemotherapy. Ann Surg Oncol. 2006; 13:624-34. [PubMed: 16538401]

7. Shen P, Hawksworth J, Lovato J, et al. Cytoreductive surgery and intraperitoneal hyperthermic chemotherapy with mitomycin $\mathrm{C}$ for peritoneal carcinomatosis from nonappendiceal colorectal carcinoma. Ann Surg Oncol. 2004; 11:178-86. [PubMed: 14761921]

8. Dedrick RL, Flessner MF. Pharmacokinetic problems in peritoneal drug administration: tissue penetration and surface exposure. J Natl Cancer Inst. 1997; 89:480-7. [PubMed: 9086004]

9. Flessner MF, Dedrick RL, Schultz JS. A distributed model of peritoneal-plasma transport: theoretical considerations. Am J Physiol. 1984; 246:R597-607. [PubMed: 6720931]

10. Rixe O, Ortuzar W, Alvarez M, et al. Oxaliplatin, tetraplatin, cisplatin, and carboplatin: spectrum of activity in drug-resistant cell lines and in the cell lines of the National Cancer Institute's Anticancer Drug Screen panel. Biochem Pharmacol. 1996; 52:1855-65. [PubMed: 8951344]

11. Atallah D, Marsaud V, Radanyi C, et al. Thermal enhancement of oxaliplatin-induced inhibition of cell proliferation and cell cycle progression in human carcinoma cell lines. Int J Hyperthermia. 2004; 20:405-19. [PubMed: 15204521]

12. Urano M, Ling CC. Thermal enhancement of melphalan and oxaliplatin cytotoxicity in vitro. Int J Hyperthermia. 2002; 18:307-15. [PubMed: 12079586] 
13. Elias D, Bonnay M, Puizillou JM, et al. Heated intra-operative intraperitoneal oxaliplatin after complete resection of peritoneal carcinomatosis: pharmacokinetics and tissue distribution. Ann Oncol. 2002; 13:267-72. [PubMed: 11886004]

14. Kuzuya T, Yamauchi M, Ito A, et al. Pharmacokinetic characteristics of 5-fluorouracil and mitomycin C in intraperitoneal chemotherapy. J Pharm Pharmacol. 1994; 46:685-9. [PubMed: 7815285]

15. Levi F, Metzger G, Massari C, et al. Oxaliplatin: pharmacokinetics and chronopharmacological aspects. Clin Pharmacokinet. 2000; 38:1-21. [PubMed: 10668856]

16. Blacher C, Neumann J, Jung LA, et al. Off-pump coronary artery bypass grafting does not reduce lymphocyte activation. Int J Cardiol. 2005; 101:473-9. [PubMed: 15907417]

17. Bolla G, Tuzzato G. Immunologic postoperative competence after laparoscopy versus laparotomy. Surg Endosc. 2003; 17:1247-50. [PubMed: 12799884]

18. Hauser GJ, Chan MM, Casey WF, et al. Immune dysfunction in children after corrective surgery for congenital heart disease. Crit Care Med. 1991; 19:874-81. [PubMed: 2055075]

19. Shen P, Levine EA, Hall J, et al. Factors predicting survival after intraperitoneal hyperthermic chemotherapy with mitomycin $\mathrm{C}$ after cytoreductive surgery for patients with peritoneal carcinomatosis. Arch Surg. 2003; 138:26-33. [PubMed: 12511145]

20. Verweij J, den Hartigh J, Stuurman M, et al. Relationship between clinical parameters and pharmacokinetics of mitomycin C. J Cancer Res Clin Oncol. 1987; 113:91-4. [PubMed: 3102501]

21. Elias D, Pocard M, Goere D. HIPEC with oxaliplatin in the treatment of peritoneal carcinomatosis of colorectal origin. Cancer Treat Res. 2007; 134:303-18. [PubMed: 17633062] 


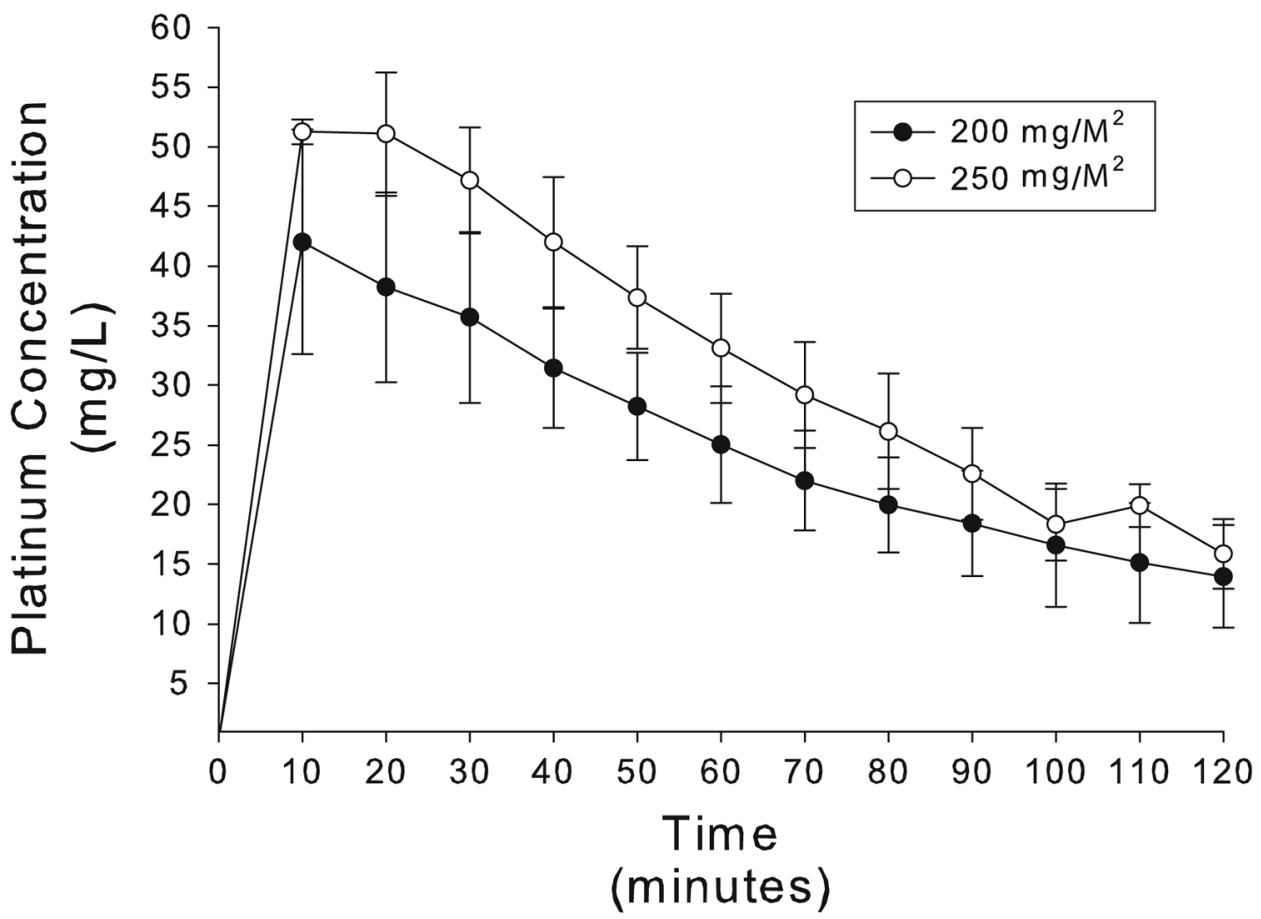

FIG. 1.

Peritoneal fluid concentration of platinum over time. 


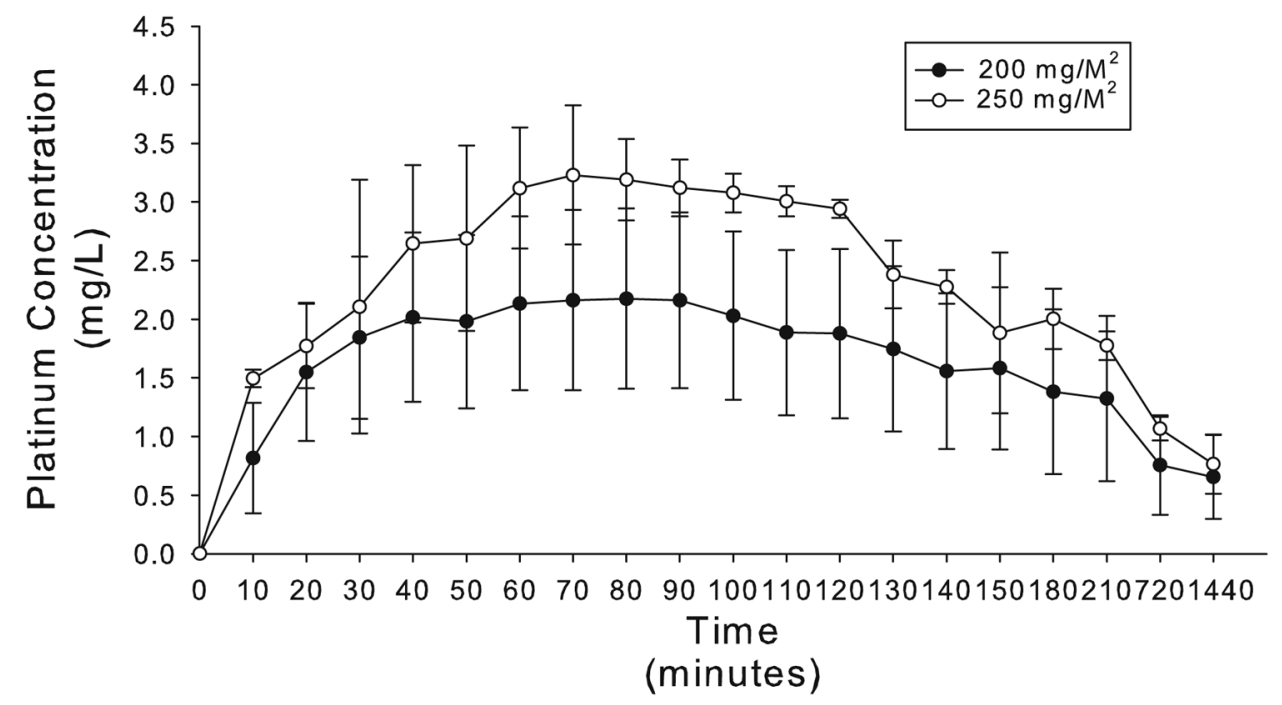

FIG. 2.

Plasma concentration of platinum over time. 
TABLE 1

Demographics of patients undergoing IPHC with oxaliplatin

\begin{tabular}{|c|c|c|c|c|}
\hline & Total & $200 \mathrm{mg} / \mathrm{M}^{2}$ & $250 \mathrm{mg} / \mathrm{M}^{2}$ & $P$-value \\
\hline Number of patients & 15 & 12 & 3 & \\
\hline \multicolumn{5}{|l|}{ Age (years) } \\
\hline Mean \pm SD & $55.5 \pm 10.9$ & $54.7 \pm 9.8$ & $58.5 \pm 16.9$ & 0.72 \\
\hline Median & 55 & 53 & 65 & \\
\hline Range & $39-73$ & $39-73$ & $39-70$ & \\
\hline \multicolumn{5}{|l|}{ Sex } \\
\hline Male & 5 & 5 & 0 & 0.51 \\
\hline Female & 10 & 7 & 3 & \\
\hline \multicolumn{5}{|l|}{ Ethnicity } \\
\hline White & 13 & 10 & 3 & 1.00 \\
\hline African-American & 2 & 2 & 0 & \\
\hline \multicolumn{5}{|l|}{ ECOG score } \\
\hline 0 & 9 & 8 & 1 & 0.60 \\
\hline 1 & 5 & 3 & 2 & \\
\hline 2 & 1 & 1 & 0 & \\
\hline \multicolumn{5}{|l|}{ Tumor type } \\
\hline Colorectal & 3 & 3 & 0 & 1.00 \\
\hline Appendiceal & 12 & 9 & 3 & \\
\hline \multicolumn{5}{|l|}{ Previous treatment } \\
\hline Chemotherapy & 7 & 7 & 0 & 0.20 \\
\hline External beam radiotherapy & 1 & 1 & 0 & 1.00 \\
\hline Debulking + IPHC & 1 & 0 & 1 & 1.00 \\
\hline \multicolumn{5}{|l|}{ Previous systemic oxaliplatin } \\
\hline Yes & 6 & 6 & 0 & 0.23 \\
\hline No & 9 & 6 & 3 & \\
\hline
\end{tabular}

SD, standard deviation. 
TABLE 2

Operative and perfusion data for patients undergoing IPHC with oxaliplatin

\begin{tabular}{|c|c|c|c|c|}
\hline & All subjects & $200 \mathrm{mg} / \mathrm{M}^{2}$ & $250 \mathrm{mg} / \mathrm{M}^{2}$ & $P$-value \\
\hline \multicolumn{5}{|c|}{ Length of operation (h:mm) } \\
\hline Mean \pm SD & $8: 39 \pm 1: 50$ & $8: 38 \pm 1: 59$ & $8: 43 \pm 1: 28$ & 0.83 \\
\hline Range & $6: 03-11: 55$ & $6: 03-11: 55$ & $7: 31-10: 22$ & \\
\hline \multicolumn{5}{|l|}{ Resection status } \\
\hline $\mathrm{R} 0 / \mathrm{R} 1$ & 9 & 8 & 1 & 0.12 \\
\hline R2a & 4 & 2 & 2 & \\
\hline $\mathrm{R} 2 \mathrm{~b}$ & 2 & 2 & 0 & \\
\hline $\mathrm{R} 2 \mathrm{c}$ & 0 & 0 & 0 & \\
\hline \multicolumn{5}{|c|}{ Temperature of perfusate $\left({ }^{\circ} \mathrm{C}\right)$} \\
\hline Mean \pm SD & $40.6 \pm 0.5$ & $40.7 \pm 0.6$ & $40.3 \pm 0.4$ & 0.25 \\
\hline Range & $39.9-42.6$ & $40.3-42.6$ & $39.9-40.1$ & \\
\hline Median & 40.5 & 40.6 & 40.4 & \\
\hline \multicolumn{5}{|c|}{ Packed red blood cells } \\
\hline Mean \pm SD & $3.3 \pm 5.0$ & $3.1 \pm 5.6$ & $4 \pm 1.7$ & 0.14 \\
\hline Range & $0-20$ & $0-20$ & $2-5$ & \\
\hline Median & 2 & 1.5 & 5 & \\
\hline
\end{tabular}


TABLE 4

Peritoneal fluid and plasma pharmacokinetics after IPHC with oxaliplatin

\begin{tabular}{|c|c|c|c|}
\hline & $200 \mathrm{mg} / \mathrm{M}^{2}$ & $250 \mathrm{mg} / \mathrm{M}^{2}$ & $P$-value \\
\hline \multicolumn{4}{|c|}{ Peritoneal fluid values } \\
\hline$t_{1 / 2}(\min )$ & $70.1 \pm 23.8$ & $65.3 \pm 10.3$ & 0.99 \\
\hline $\mathrm{C}_{\max }(\mathrm{mg} / \mathrm{L})$ & $42.0 \pm 9.4$ & $51.3 \pm 1.1$ & 0.11 \\
\hline $\mathrm{C}_{\min }(\mathrm{mg} / \mathrm{L})$ & $14.0 \pm 4.3$ & $15.9 \pm 2.9$ & 0.44 \\
\hline $\operatorname{AUC}(\mathrm{mg} / \mathrm{L} \mathrm{h})$ & $49.6 \pm 8.6$ & $62.7 \pm 10.2$ & 0.09 \\
\hline \multicolumn{4}{|l|}{ Plasma values } \\
\hline$t_{1 / 2}(\min )$ & $94.2 \pm 64.8$ & $61.2 \pm 5.0$ & 0.52 \\
\hline $\mathrm{C}_{\max }(\mathrm{mg} / \mathrm{L})$ & $2.2 \pm 0.77$ & $3.2 \pm 0.6$ & 0.03 \\
\hline $\mathrm{C}_{\min }(\mathrm{mg} / \mathrm{L})$ & $0.66 \pm 0.4$ & $0.77 \pm 0.3$ & 0.72 \\
\hline $\operatorname{AUC}(\mathrm{mg} / \mathrm{L} \mathrm{h})$ & $23.2 \pm 11.4$ & $31.1 \pm 3.0$ & 0.22 \\
\hline
\end{tabular}

Values are expressed as the mean \pm standard deviation.

$t_{1 / 2}$, half life; $\mathrm{C}_{\max }$, maximum concentration of drug; $\mathrm{C}_{\min }$, minimum concentration of drug; AUC, area under the curve. 
TABLE 5

Tissue and plasma levels at the conclusion of IPHC

\begin{tabular}{lccc}
\hline & $\mathbf{2 0 0} \mathbf{~ m g / \mathbf { M } ^ { 2 }}$ & $\mathbf{2 5 0} \mathbf{~ m g} / \mathbf{M}^{\mathbf{2}}$ & $\boldsymbol{P}$-value \\
\hline Peritoneal fluid $(\mathrm{mg} / \mathrm{L})$ & $14.2 \pm 4.2$ & $15.9 \pm 2.9$ & 0.47 \\
Plasma $(\mathrm{mg} / \mathrm{L})$ & $0.7 \pm 0.3$ & $0.8 \pm 0.3$ & 0.88 \\
Normal tissue $(\mu \mathrm{g} / \mathrm{g})$ & $17.7 \pm 10.8$ & $26.3 \pm 14.7$ & 0.35 \\
Tumor $(\mu \mathrm{g} / \mathrm{g})$ & $15.9 \pm 12.0$ & $20.3 \pm 9.7$ & 0.48 \\
\hline
\end{tabular}

Values are expressed as the mean \pm standard deviation. 
TABLE 6

Peritoneal and plasma oxaliplatin exposure during IPHC

\begin{tabular}{lccl}
\hline & $\mathbf{2 0 0} \mathbf{~ m g} / \mathbf{M}^{\mathbf{2}}$ & $\mathbf{2 5 0} \mathbf{~ m g} / \mathbf{M}^{\mathbf{2}}$ & $\boldsymbol{P}$-value \\
\hline $0-60 \mathrm{~min}$ & & & \\
$\mathrm{AUC}_{\text {peritoneal fluid }}(\mathrm{mg} / \mathrm{L} \mathrm{h})$ & $30.9 \pm 5.69$ & $39.1 \pm 6.2$ & 0.09 \\
$\mathrm{AUC}_{\text {plasma }}(\mathrm{mg} / \mathrm{L} \mathrm{h})$ & $1.5 \pm 0.54$ & $1.9 \pm 0.5$ & 0.16 \\
$\mathrm{AUC}_{\text {peritoneal fluid/plasma }}$ & $20.0 \pm 6.6$ & $21.5 \pm 3.1$ & 0.76 \\
$60-120$ min & & & \\
$\mathrm{AUC}_{\text {peritoneal fluid }}(\mathrm{mg} / \mathrm{L}$ h) & $18.6 \pm 4.1$ & $23.4 \pm 3.9$ & 0.09 \\
$\mathrm{AUC}_{\text {plasma }}(\mathrm{mg} / \mathrm{L} \mathrm{h})$ & $124.2 \pm 42.5$ & $180.7 \pm 6.3$ & 0.22 \\
$\mathrm{AUC}_{\text {peritoneal fluid/plasma }}$ & $9.1 \pm 3.9$ & $7.8 \pm 1.6$ & 0.99 \\
$0-120$ min & & & \\
$\mathrm{AUC}_{\text {peritoneal fluid }}(\mathrm{mg} / \mathrm{L} \mathrm{h})$ & $49.6 \pm 8.6$ & $62.7 \pm 10.2$ & 0.036 \\
$\mathrm{AUC}_{\text {plasma }}(\mathrm{mg} / \mathrm{L}$ h) & $3.6 \pm 1.2$ & $4.9 \pm 0.54$ & 0.036 \\
$\mathrm{AUC}_{\text {peritoneal fluid/plasma }}$ & $13.7 \pm 4.7$ & $12.8 \pm 3.1$ & 0.99 \\
\hline
\end{tabular}

AUC, area under the curve.

Values are expressed as the mean \pm standard deviation. 